S Berman. Children's Hospital, University of Colorado School of Medicine, Aurora, CO, USA

Pediatricians and other clinicians who care for children around the globe are aware of the need to address the social determinates of childhood illness and advocate for children and their families living in their communities. Pediatricians have a unique perspective on the health and wellbeing of children and families living in their communities since they are the only professionals who routinely care for and follow preschool children. Pediatricians throughout the world are usually highly regarded by families and respected within their communities. Because of this respect, they have special opportunities to influence child and family policy.

Advocacy is defined by the 4 P's: personal experience, persistence/patience, passion, and principles. Personal experience usually determines the population or issue for which you decide to advocate. An effective advocate must be persistent and patient because it is difficult to change both policy and health care systems. Passion is also necessary for effective advocacy. An effective advocate feels personally connected to his or her issue. The final $\mathrm{P}$ in advocacy is to be principled. This means having a strong sense of integrity, credibility, fairness, and responsibility. Having integrity means a commitment to gain as complete an understanding of the issue as possible. Having credibility means that you will serve the best interests of children. Being fair means your policy recommendations will be based on a uniform standard of care for all children. Finally being responsible means recognizing how the consequences of the policy or advocacy efforts might have unintended effects.

\section{WHY IS IT IMPORTANT TO INVEST IN PAEDIATRIC HEALTH CARE?}

doi:10.1136/archdischild-2012-302724.0096

F Waldhauser. Platform Political Paediatrics ('Politische Kindermedizin'), Vienna, Austria

The knowledge about a positive correlation between life expectancy and gross domestic product (GDP) is a commonplace. Also a positive correlation between mortality of children less than 5 yrs (U5MR) and health expenditure is well established. The drastic difference in child mortality between economically developed and economically underdeveloped countries is a point in case. Likewise, after the first gulf war child mortality increased by more than 100\% in Iraq on economic sanctions.

In economically developed countries, which finance their health system sufficiently, a fundamental question is whether this money does arrive at all patients, who need it, or does it get lost for supplementation of outdated structures, bureaucracy and administration or for unjustified profits of stakeholders. For example, health expenditure and child mortality are $16.0 \%$ (GDP) and $7.8 \%$ o (U5MR) in the USA vs. 9.1 and 3.0 in Sweden. In the early 2000's Eastern Austria supplied 1.385 hospital beds for its sick children, the German part of Switzerland (with a similar population of just below 5 millions) supplied 762 beds, although U5MR was the same (5.5\%; in 2001 ) in both countries.

However, because of a dramatic lake of international, comparable data it is difficult to pinpoint strength and weaknesses of paediatric health care systems of different countries.

In coming years, child advocacy should fight for

a. adequate economic support of paediatric health care,

b. for the direct benefit of all sick children from health expenditure and

c. for provision of international comparable data on paediatric patients.
97 WHAT IS THE ASSOCIATION BETWEEN SCREEN TIME AND OUTCOMES FOR CANADIAN CHILDREN?

doi:10.1136/archdischild-2012-302724.0097

1,2SC Tough, 'SW McDonald, ${ }^{1,3} \mathrm{M}$ Vekved, ${ }^{4} \mathrm{~K}$ Benzies, ${ }^{1} \mathrm{M}$ Hicks, ${ }^{3} \mathrm{~J}$ Siever. ${ }^{1}$ Paediatrics; ${ }^{2}$ Community Health Sciences, University of Calgary; ${ }^{3}$ Public Health Innovation and Decision Support, Alberta Health Services, ${ }^{4}$ Nursing, University of Calgary, Calgary, $A B$, Canada

Background and aims To determine the association between screen time and child outcomes.

Methods 706 mothers who were part of a longitudinal pregnancy cohort were mailed a questionnaire when children were 6 to 8 years of age. Mothers reported the amount of time children spent with computers, television, and video games on an average school day (screen time), BMI, child behavior, and physical activity. Using Pearson chi-square tests or independent sample t-tests, children who had more than 2 hours screen time on an average school day were compared to those who had 2 hours or less.

Results 450 mothers completed the questionnaire (response rate $64 \%$ ). $30 \%$ of children had more than 2 hours of screen time during school days, and these children were more likely to take longer than 30 minutes to fall asleep ( $25 \%$ vs. $15 \%$, $p=0.006$ ) and less likely to exhibit prosocial behavior (mean 12.88 vs. 13.71, $\mathrm{p}=0.028$ ). There was no association between screen time and BMI or time spent in physical activity. Compared to mothers of children had 2 hours or less of screen time, mothers of children who had more than 2 hours of screen time were less likely to be satisfied with their child's level of physical activity (76\% vs. $89 \%$, p<0.001).

Conclusions The Canadian Paediatric Society guideline recommends no more than 2 hours of screen time per day. More than a third of children exceed this limit on school days, and this may have important implications for children's sleep and behavior in childhood.

\section{LEAD, MERCURY AND CADMIUM LEVELS IN CORD BLOOD, BREAST MILK AND NEWBORN HAIR}

doi:10.1136/archdischild-2012-302724.0098

${ }^{1} \mathrm{~A}$ Dursun, ${ }^{1} \mathrm{~K}$ Yurdakok, ${ }^{1} \mathrm{SS}$ Yalcin, ${ }^{1} \mathrm{G}$ Tekinalp, ${ }^{2} \mathrm{O}$ Aykut, ${ }^{2} \mathrm{G}$ Orhan, ${ }^{2} \mathrm{GK}$ Morgil. ${ }^{1}$ Department of Pediatrics, Hacettepe University Faculty of Medicine; ${ }^{2}$ Analytic Toxicology Laboratory, Refik Saydam National Public Health Agency, Ankara, Turkey

Background and aim Lead, mercury and cadmium are widely exposed environmental pollutants throughout the world. In this study, we aimed to investigate the level of exposure to lead( $(\mathrm{Pb})$, mercury $(\mathrm{Hg})$ and cadmium $(\mathrm{Cd})$ during intrauterine life.

Methods We included 123 mother-infant pairs between December 2006 and January 2007. Umbilical cord blood collected immediately after delivery while breast milk and newborn hair samples collected between $3-10^{\text {th }}$ postpartum days. All the specimens analyzed by Inductively Coupled Plasma Mass Spectrometry.

Results Cord blood samples $\mathrm{Pb}$ was present in $99.2 \%$ (the mean $1.66 \pm 1.6 \mu \mathrm{g} / \mathrm{dl}$ ) while $\mathrm{Hg}$ in only $1.7 \%$ and $\mathrm{Cd}$ in $19.8 \%$ (ranged $0-6.71 \mu \mathrm{g} / \mathrm{L})$. Cord blood $\mathrm{Pb}$ was higher than $\geq 2 \mu \mathrm{g} / \mathrm{dl}$ in $29 \%$ of the samples. $\mathrm{Pb}, \mathrm{Hg}$ and $\mathrm{Cd}$ were detectable in all the newborn hair samples. Among breast milk samples $83.2 \%$ had detectable lead levels(mean $14.5 \pm 12.1 \mu \mathrm{g} / \mathrm{L}$ ). Presence of $\mathrm{Hg}$ and $\mathrm{Cd}$ in breast milk samples were $53.3 \%$ and $9 \%$ respectively. Cord blood lead levels were significantly higher when maternal age $>35$ years. Breast milk Cd levels were significantly higher in women who were residing close to the major city waste site. Cord blood Cd levels were significantly higher in women consuming more than two fish weekly. Maternal exposure to environmental tobacco smoking(ETS) resulted increased newborn hair $\mathrm{Pb}$ and $\mathrm{Cd}$ levels.

Conclusion Intrauterine heavy metal exposure is an important concern for pediatricians. Most samples had detectable levels for $\mathrm{Pb}$ $\mathrm{Hg}, \mathrm{Cd}$ indicating long term maternal exposure and considerable 